\title{
Experimental Evaluation of Some Controversial Points Regarding the A-V Conduction Disturbances in the Clinical His Bundle Electrogram
}

\author{
Kazumasa Hiejrma, M.D. and Fumio Suzuki, M.D.
}

\begin{abstract}
SUMmaRY
Although the recordings of the His potential have been shown to be very useful in the study of cardiac conduction and rhythm disturbances, there remain some problems regarding the clinical His bundle electrogram. Some of the studies were performed to solve in the perfused dog hearts and in situ dog hearts, and consequently the following results were obtained. In some experiments, recording of the His potential could not be achieved even in the perfused hearts in spite of the preserved $A-V$ conduction, suggesting that, as experienced sometimes in the clinical cases, inability to record the His potential might not be due to the technical failure or the anatomical abnormalities of the His bundle. On the other hand, real " splitting of $\mathrm{H}$ " occurred in association with the increase in the duration and decrease in the amplitude of the His potential after the ligation of the anterior septal artery. In addition, the true Mobitz II type A-H block, and Wenckebach type intra-Hisian and $\mathrm{H}-\mathrm{V}$ block could be produced experimentally.
\end{abstract}

\section{Additional Indexing Words :}

"Splitting of $\mathrm{H} " \quad$ His bundle pacing Mobitz II type A-H block Wenckebach type intra-Hisian block Wenckebach type $\mathrm{H}-\mathrm{V}$ block

\begin{abstract}
A great deal of information has been obtained by the development of the His bundle recordings. One of the contributions of the His bundle recordings is the more accurate localization of the site of the conduction abnormality in the patients with various forms of A-V block. Frequent controversies occurred on several points concerning the His bundle electrogram. ${ }^{1-7)}$ Some of them are performed to be solved in the perfused $\mathrm{dog}$ hearts and in situ dog hearts.
\end{abstract}

\section{Materials and Methods}

Series 1. Twenty adult mongrel dogs were anesthetized with intravenous

From the Department of Internal Medicine and Institute for Cardiovascular Diseases, Tokyo Medical and Dental University, Tokyo, Japan.

Address for reprints: Kazumasa Hicjima, M.D., Department of Internal Medicine, Tokyo Medical and Dental University, 5-45, 1-Chome, Yushima, Bunkyo-ku, Tokyo, Japan.

Received for publication November 26, 1974. 
sodium pentobarbital $(30 \mathrm{mg} / \mathrm{Kg})$. The hearts were removed rapidly by median thoracotomy and placed in the cool oxygenated Tyrode solution of the following composition (mM): $\mathrm{HaHCO}_{3} 12 ; \mathrm{NaHPO}_{4} 4.6 ; \mathrm{NaCl}$ 13.7; $\mathrm{KGl}$ 4.6; $\mathrm{CaCl}_{2} 1.8$; $\mathrm{MgCl}_{2} 0.5$; and glucose 5.5. The hearts were perfused by means of the modified Langendorff technique; the bath was perfused continuously with Tyrode solution which was gassed with $95 \% \mathrm{O}_{2}$ and $5 \% \mathrm{CO}_{2}$ and the temperature of the perfusate was maintained between 34 to $36^{\circ} \mathrm{C}$. The right atrium and ventricle were opened longitudinally to expose the right side of the interatrial and interventricular septa. A plaque electrode was attached to the epicardium of the right atrium to record the atrial electrical activity and apply the driving stimuli. A 4-pole electrode catheter of $20 \mathrm{~cm}$ in length was inserted into the inferior vena cava and positioned over the region of the attachment of the tricuspid valve to record the His potential. A silver electrode was placed on the right bundle branch to record its activity.

A- $\mathrm{V}$ conduction disturbances were produced by the injection of 30 to $120 \mathrm{mM}$ of $\mathrm{KCl}$ solution, $0.5 \%$ of lidocaine or formaldehyde solution into the His bundle region or by directly incising the region. The His and right bundle branch potentials were obtained before and after the production of various degrees of $\mathrm{A}-\mathrm{V}$ conduction abnormality.

Series 2. Twenty adult mongrel dogs were anesthetized with intravenous sodium pentobarbial $(30 \mathrm{mg} / \mathrm{Kg})$, intubated and connected to an artificial respirator. The dogs were secured in the right lateral position. A thoracotomy was performed through the left fourth intercostal space, and the lateral surface of the right atrium and basal portion of the right ventricle were exposed. The pericardium was incised and the heart was positioned by a pericardial cradle. The bifurcation of the left coronary artery was exposed, removing by retracting the tip of the left atrial appendage. The anterior septal artery was explored, removing the tissues enclosing the proximal portions of the anterior descending and left circumflex arteries. Then, double ligation of the anterior septal artery was performed. The His bundle potential was recorded by a bipolar electrode catheter according to Scherlag. ${ }^{8)}$ Lead II electrocardiogram and His bundle electrogram were monitored on the oscilloscope before and up to 10 hours after ligation. When necessary, a polyvinyl cannula was inserted into the anterior septal artery several hours after ligation and various agents, i.e., lidocaine $(0.5 \%), \mathrm{KCl}(1 \mathrm{mEq} / \mathrm{ml})$ and propranolol $(1 \mathrm{mg} / \mathrm{ml}$ ) werc administered through the cannula.

\section{Results}

In the perfusion experiments on the isolated heart (Series 1), the A-H block proximal to the His bundle occurred in all the preparations by injecting various agents into the His bundle region. In the experiments of Series 2,15 of 20 dogs survived after the ligation of the anterior septal artery. A-V conduction disturbance developed within 1 hour after ligation in almost all the dogs. The left axis deviation appeared in $10 \mathrm{dogs}$ and an increase in the duration of the QRS complex in one of the dogs. Finally, the H-V block developed within 10 hours after ligation.

Observation 1. In some perfused experiments, the amplitude of the 


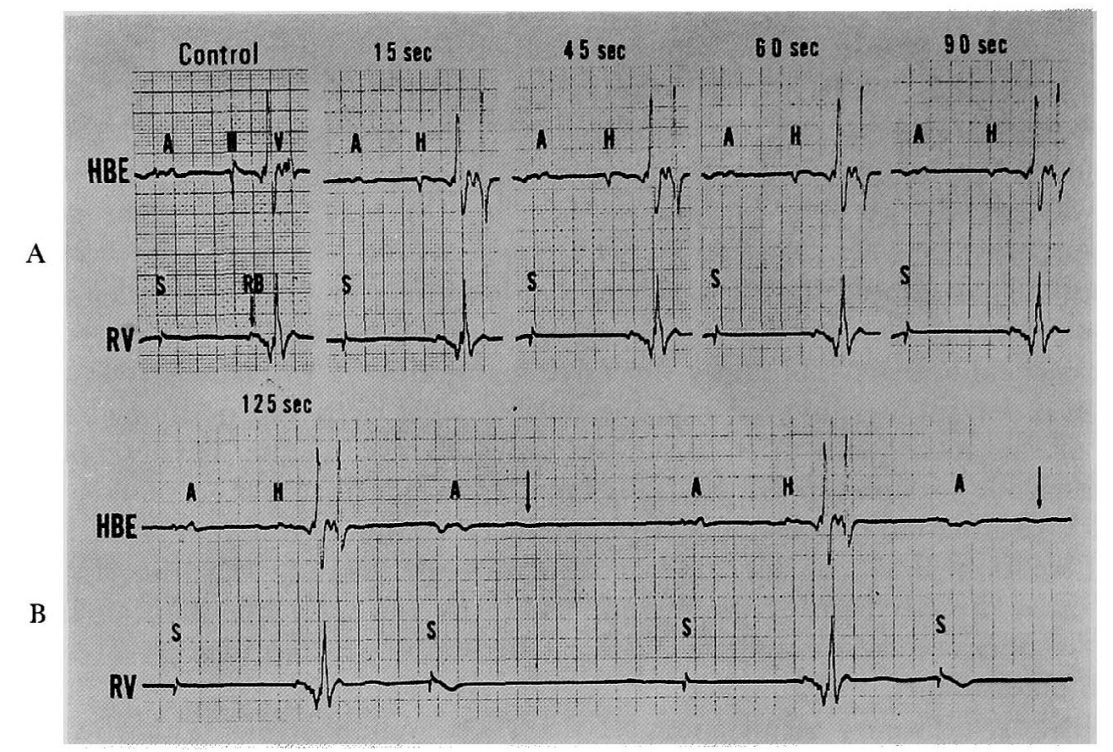

Fig. 1. Progressive decrease in the amplitude of $\mathrm{His}$ potential (A) and the A-H block (b), after injection of $\mathrm{KCl}$ into the His bundle region. A: Note that there are no changes in the $\mathrm{A}-\mathrm{H}$ and $\mathrm{H}-\mathrm{V}$ interval. B: A tiny wave preceding the decreased His potential may be one of the split His potentials.

HBE: His bundle electrogram; RV: right ventricular electrogram; A: atrial potential; $\mathrm{H}$ : His bundle potential; RB: right bundle branch potential; $\mathrm{V}$ : ventricular potential; and $\mathrm{S}$ : driving stimulus.

His bundle deflection ( $\mathrm{H}$ deflection) decreased progressively after the injection of $\mathrm{KCl}(120 \mathrm{mM}, 0.1 \mathrm{ml})$ into the His bundle region, although the A-V conduction persisted (Fig. 1). It is only $125 \mathrm{sec}$ after the injection that the A-H interval was prolonged and the A-V block occurred above the His bundle. In the other experiments with the perfused hearts, cutting of the His bundle was performed with a sharp knife. As a result the $\mathrm{H}$ deflection disappeared, although the A-V conduction still persisted (Fig. 2). These observations suggest that the His bundle, even if directly injured, is so resistant to the conduction disturbance that the disappearance of the $\mathrm{H}$ deflection is likely to occur in spite of the persistency of the A-V conduction. Therefore, when the recording of the $\mathrm{H}$ deflection cannot be achieved despite the repeated challenges, the cause may not be simply attributable to the technical failure.

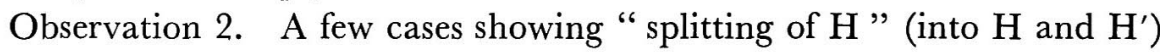
have been reported clinically. It has been an open question, however, whether or not the $\mathrm{H}^{\prime}$ deflection is a potential produced by the distal part of the His bundle. Fig. 3 shows the complete A-V block induced by the injection of the formalin solution into the His bundle region in the perfused heart. The 
subsidiary pacemaker is located in the His bundle. In this experiment the negative deflection (shown as $\mathrm{RB}$ ) after the $\mathrm{H}$ potential in the middle tracing is roughly consistent with the positive deflection before the $\mathrm{V}$ potential in the bottom tracing, which was simultaneously taken when a silver electrode

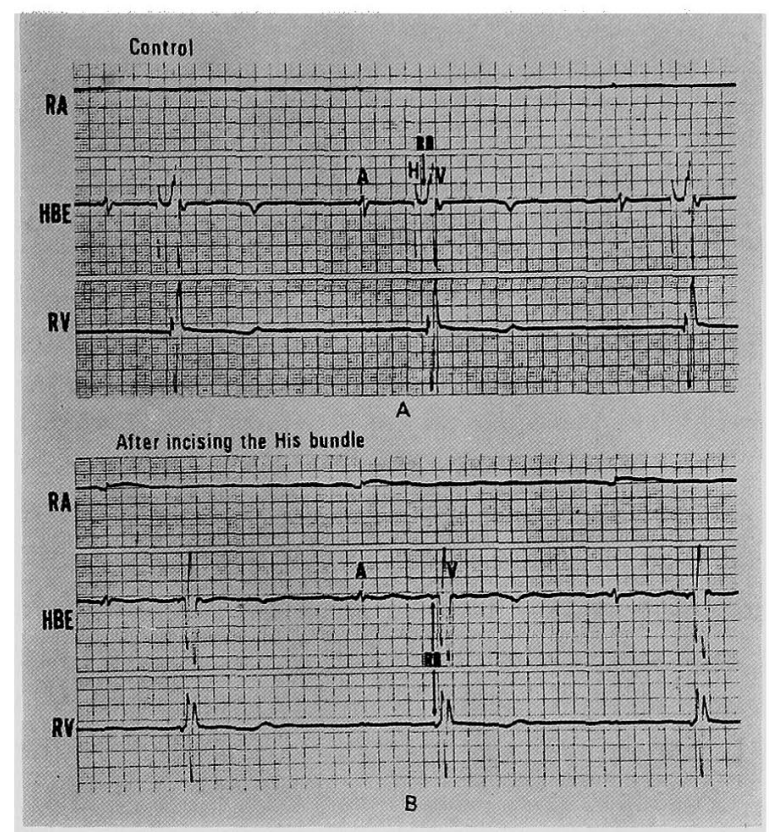

Fig. 2. Partial cutting of the His bundle. A: Control. B: After incising the His bundle. Note that the His potential has disappeared, although the A-V conduction was well preserved. RA: right atrial electrogram.

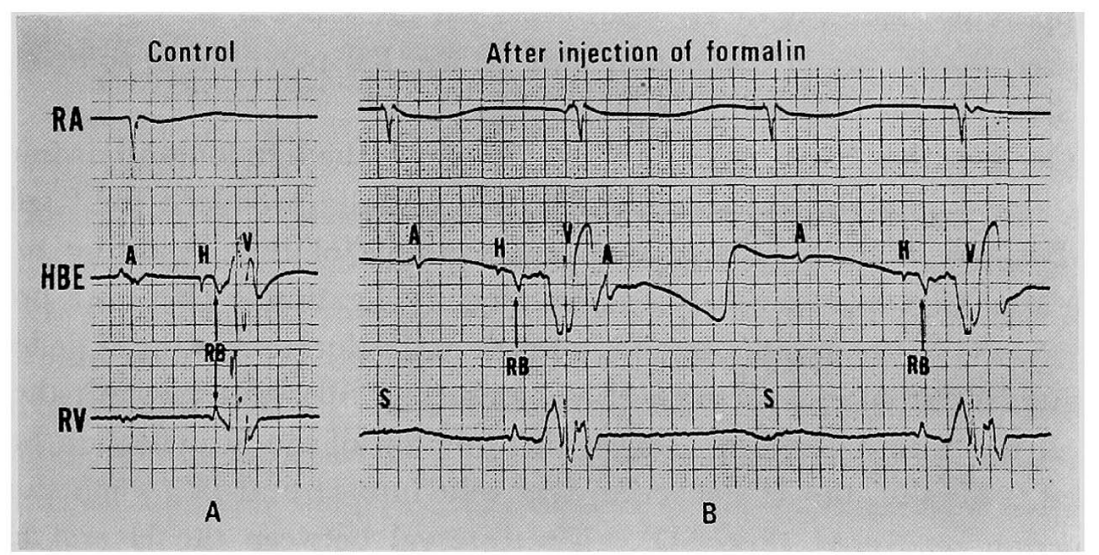

Fig. 3. Prolongation of the H-RB and RB-V interval after injection of formalin solution into the His bundle region. A: Control. B: His bundle rhythm after injection. The H-RB and RB-V interval were prolonged by $12 \mathrm{msec}$ and $27 \mathrm{msec}$, respectively. 


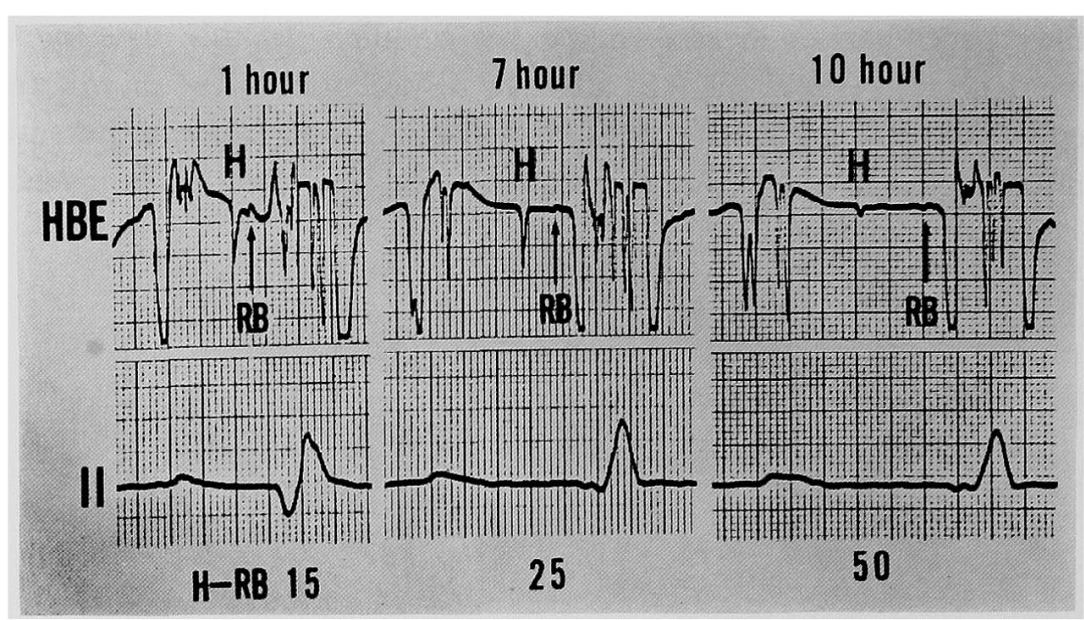

Fig. 4. Prolongation of the H-RB interval after ligation the anterior septal artery. The H-RB interval was prolonged from $15 \mathrm{msec}$ to $50 \mathrm{msec}$ 10 hours later. II : Lead II electrocardiogram.

was placed on the right bundle branch. Consequently, both were considered to be right bundle potential. The distance between the right bundle branch potential (RB) and ventricular potential (V) is markedly prolonged, being associated with the change in the configuration of the $\mathrm{V}$ wave (Fig. 3B). Such a $\mathrm{H}$ or RB potential is not necessarily followed by the changes in the QRS complex. For example, as is shown in Fig. 4, a similar RB potential was seen when the QRS complex in Lead II did not seem to be abnormal 7 and 10 hours after the ligation of the anterior septal artery. The H-RB interval lengthens from $15 \mathrm{msec}$ to $50 \mathrm{msec}$. These observations suggest that the apparent "splitting of $\mathrm{H}$ " can occur on the His bundle electrogram, in the other words, the $\mathrm{H}^{\prime}$ deflection may be the RB potential in some clinical cases showing the "splitting of $\mathrm{H}$ ".

On the other hand, there are cases in which the ligation and/or injection of the agents into the anterior septal artery actually produced the "splitting of $\mathrm{H}$ ". Fig. 5 shows a representative example of the "splitting of $\mathrm{H}$ ", which appeared spontaneously 4 hours after the ligation. There is a progressive decrease in the amplitude and increase in the duration of the $\mathrm{H}$ deflection, resulting in the Mobitz II type $\mathrm{H}-\mathrm{V}$ block (Fig. 5B). In Fig. 5C, the A-H interval was also prolonged and the deformation of the $\mathrm{H}$ deflection became marked. Finally, the $\mathrm{H}$ deflection was split into $\mathrm{H}$ and $\mathrm{H}^{\prime}$, when the $\mathrm{A}-\mathrm{V}$ conduction recovered (Fig. 5D). The interval between the $\mathrm{H}$ and $\mathrm{H}^{\prime}$ deflection is about 50 msec. As seen in Fig. 5, it was frequently observed that, when the intra-Hisian block was present, an increase in the duration and decrease in the amplitude of the $\mathrm{H}$ and $\mathrm{H}^{\prime}$ deflection occurred. 


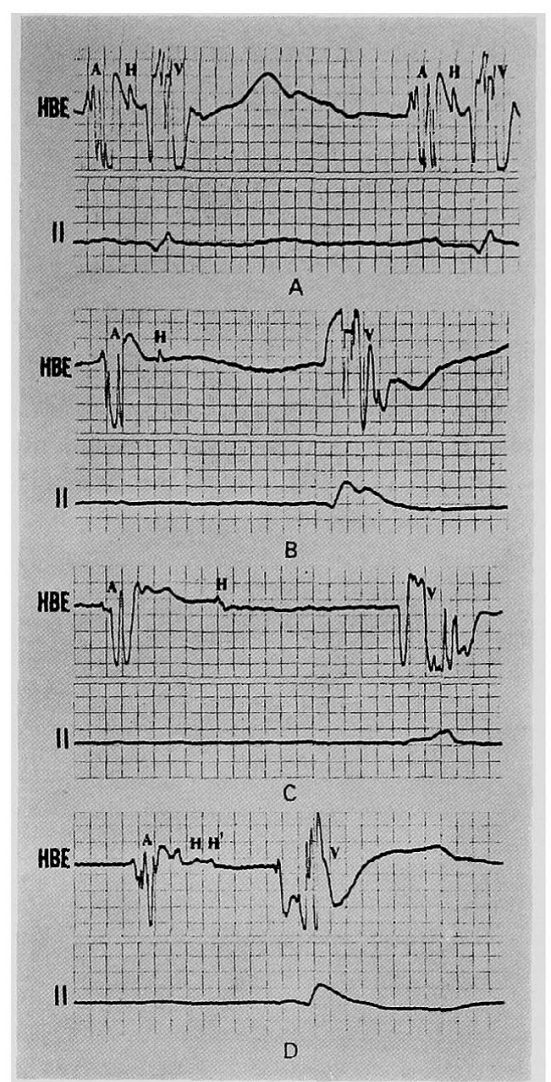

Fig. 5. Intra-Hisian delay and block after ligation of the anterior septal artery. A: Control. B: H-V block 3 hours after ligation. Amplitude of the His potential was markedly decreased. C: Intra-Hisian delay at 3.4 hours after ligation. D: Intra-Hisian block ("splitting of $\mathrm{H}$ ") at 4 hours after ligation. Amplitude of the His potential became smaller. The A-V conduction returned at the expense of the conduction delay in the $\mathrm{H}-\mathrm{V}$ interval.

Observation 3. Various types of block which have been said to be rare clinically were observed. Being different from the usual clinical experiences, there was the advantage that the localization and mode of appearance of the block could be observed directly. In 1 case the Mobitz II type A-V block appeared, as shown in Fig. 6, when acetylcholine $(1 \mathrm{mg} / \mathrm{ml}, 1 \mathrm{ml})$ was administered into the right coronary artery of the perfused heart. The shortened A-H interval following the pause, as observed in this experiment, is not a rare phenomenon in the Mobitz II type A-V block.

In another experiment, the Wenckebach type A-V block occurred in the His bundle as shown in Fig. 7, when lidocaine was applied about 10 hours after the ligation. As time passed, both the increase in the duration and 


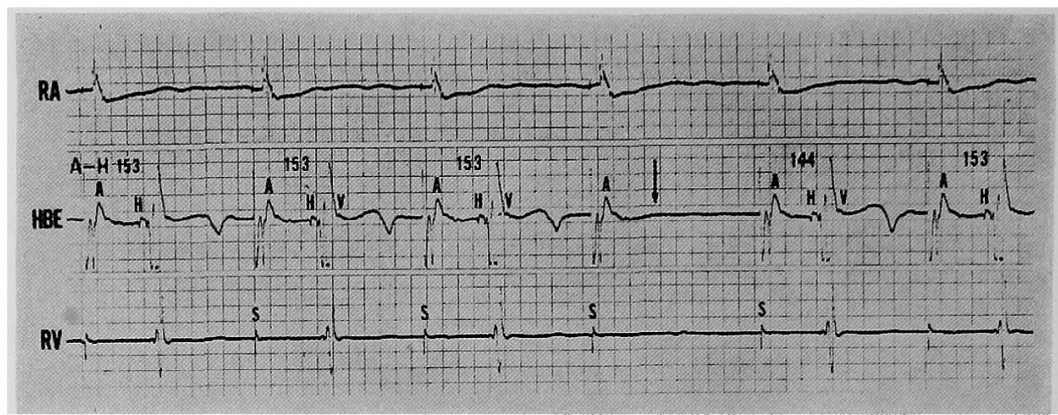

Fig. 6. Mobitz II type A-H block after injection of acetylcholine into the right coronary artery. The A-H interval was fixed $(153 \mathrm{msec})$ preceding the dropped beat (indicated by arrow).

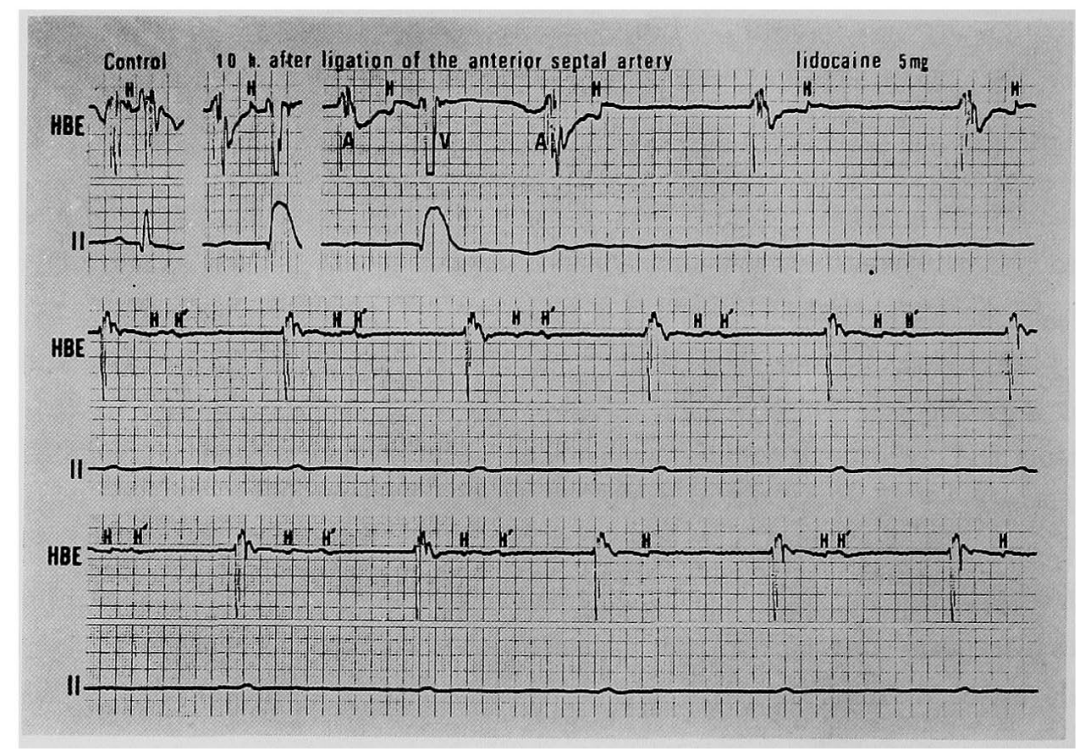

Fig. 7. Wenckebach phenomenon in the His bundle. Upper tracing, left: control; middle: changes of the His potential and QRS complex 10 hours after ligation; right: Wenckebach phenomenon in the His bundle following injection of $5 \mathrm{mg}$ of lidocaine into the anterior septal artery. Dropping of $\mathrm{H}^{\prime}$ potential occurred in the bottom tracing (3 tracings are continuous).

decrease in the amplitude of the $\mathrm{H}$ deflection developed, resulting in the "splitting of $\mathrm{H}$ ". The following $\mathrm{H}-\mathrm{H}^{\prime}$ interval lengthened progressively until the $\mathrm{H}^{\prime}$ deflection disappeared. The following $\mathrm{H}-\mathrm{H}^{\prime}$ interval was short with progressive prolongation. This finding is consistent with the Wenckebach phenomenon.

Fig. 8 exhibits the Wenckebach type A-V block in the His-Purkinje system induced by the His bundle pacing in the perfused heart. This is atypical, 


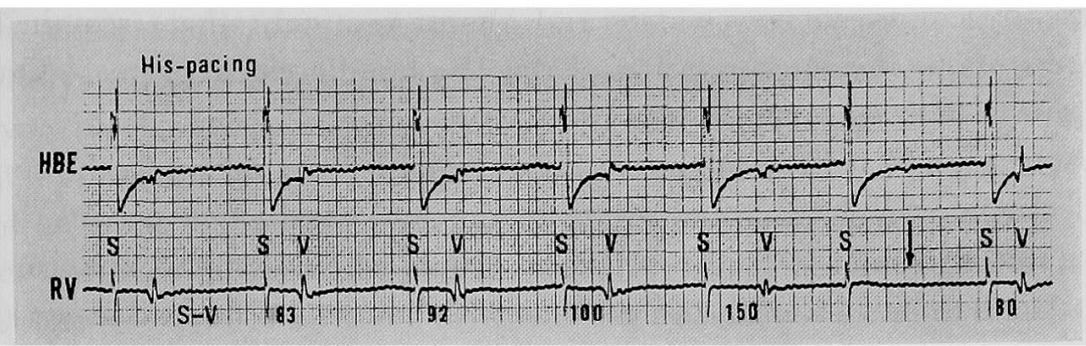

Fig. 8. Wenckebach type $\mathrm{H}-\mathrm{V}$ block induced by $\mathrm{His}$ bundle pacing. Note the maximal increment in the $\mathrm{H}-\mathrm{V}$ interval immediately preceding the dropped beat (indicated by arrow).

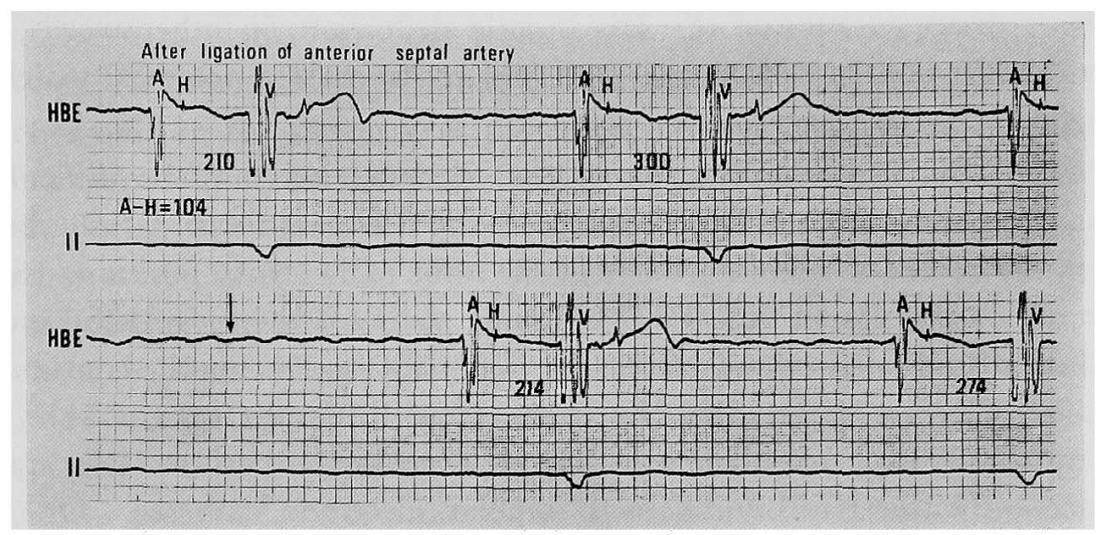

Fig. 9. Wenckebach type H-V block after ligation of the anterior septal artery. Two tracings are continuous. The $\mathrm{H}-\mathrm{V}$ interval shows progressive prolongation (210-300 msec) and dropped $\mathrm{V}$ wave ocsurred at the location indicated by an arrow ( $3: 2$ Wenckebach period).

since the maximal increment occurred in the $\mathrm{H}-\mathrm{V}$ interval preceding the dropped beat. Fig. 9 shows the classic Wenckebach type A-V block in the His-Purkinje system produced by the ligation. The conduction ratio of the Wenckebach period is $3: 2$.

\section{Discussion}

The His bundle electrogram has contributed to a more exact localization of the A-V block. The His bundle electrogram is particularly useful in differentiating the 2 types of second degree A-V block. By using this technique, it has been ascertained in the living human that the conduction disturbances can occur in any region of the $\mathrm{A}-\mathrm{V}$ conduction system; namely, clinical cases, which were difficult or impossible to be diagnosed exactly by the surface electrocardiogram and consequently thought to be rare, were found to exist occasionally by recording the His bundle potentials. Although this technique 
is clinically employed now widely and almost routinely, there remain some problems about the interpretation of the His bundle electrograms. Our results give a basis to some of such problems.

When the $\mathbf{H}$ deflection cannot be recorded by any means in the conventional His bundle electrogram, although the A-V conduction persists, it may be usually attributable to the technical failure or anatomical abnormalities of the His bundle as seen in the patients with congenital heart diseases (as in the endocardial cushion defect, corrected transposition of the great arteries). ${ }^{9}$ ' It was shown, however, that in some experiments the A-V conduction, especially the conduction in the His-Purkinje system, remained good, despite the apparent disappearance of the His bundle deflection, in other words, even when the His bundle cells were insufficient to generate a potential which can be recorded by extracellular methods.

Clinically, the identification of the $\mathrm{H}$ deflection may be difficult occasionally, unless both the deflections of the His bundle and right bundle branch are recorded simultaneously in the same catheter-tip position. Scherlag et $a^{(5), 10)}$ postulated that the His bundle pacing is the most useful method to validate the $\mathrm{H}$ deflection. Difficulty of pacing the His bundle continuously has been, however, pointed out by Rosen et al11),12) and Gupta et al. ${ }^{13)}$ According to our experiment, it was difficult even in the perfused preparations to pace only the His bundle by a bipolar electrode catheter. One may doubt, therefore, in the clinical cases in which the "splitting of $\mathrm{H}$ " has been asserted to be present, ${ }^{10), 11), 14 /-18)}$ whether the $\mathrm{H}^{\prime}$ deflection is actually one of the split His bundle potentials or of the right bundle branch potentials. Our results showed that a case may be present in which the second deflection is the right bundle branch potential. Recently, Varghese et al ${ }^{19)}$ demonstrated by a gentle pressure applied to the His bundle with the tip of a needle that a significant intra-His bundle conduction delay resulted in $2 \mathrm{H}$ deflections in the extracellular electrogram recordings. We also demonstrated in the dog hearts in site that the His bundle potential is actually split into 2 deflections. From the observations on our experiments, it can be suggested that, if the amplitude of both the $\mathrm{H}$ and $\mathrm{H}^{\prime}$ potentials is decreased, as compared with the other deflections recorded by the His bundle electrogram, real "splitting of $H$ " is more likely to be the case.

Although the exact mechanism of the Wenckebach and Mobitz II type A-V block remains uncertain, the mode of the induction of the block is easy to understand by recording the His bundle electrogram. Up to date, the most usual clinical observations and experimental experiences are that the Wenckebach type A-V block occurs in the A-V node and the Mobitz II type A-V block occurs in the His-Purkinje system. ${ }^{20), 21)}$ With the accumulation 
of the clinical His bundle electrograms, however, it has been found not to be always true. For instance, clinical cases were found in which the Mobitz II type block seemed to have occurred in the A-V node. 14),22),23) Experimentally, Spear and Moore demonstrated that the Mobitz II type A-H block could be easily induced in the normal hearts by slight variations in the atrial cycle. Moreover, they also produced by administering a toxic dose of ouabain a Mobitz II type A-H block without the antecedent changes in the A-V conduction, as shown in our experiment (Fig. 6). The mechanism, by which the Mobitz II type A-H block was induced following administration of these agents, is not clear, because these agents usually induce the Wenckebach type A-H block. On the other hand, the Wenckebach phenomenon has been electrocardiographically demonstrated to occur in the bundle branches only in the recent rare reports, ${ }^{25)-27)}$ although Scherf and Shookhoff ${ }^{28)}$ experimentally demonstrated a Wenckebach phenomenon in the bundle branch system after destroying one bundle branch and slightly damaging the other, and Cranefield et $\mathrm{al}^{29)}$ produced a block in the depressed isolated segment of the canine Purkinje fibers. By the His bundle electrogram, the Wenckebach phenomenon has been also documented to occur in the HisPurkinje system in the patients with a bundle branch block. ${ }^{14), 15)}$ Although a few cases ${ }^{10), 11,14)-18}$ have been reported in which the Wenckebach phenomenon was asserted to have occurred in the His bundle, the Wenckebach type A-V block was demonstrated in our experiments to occur by taking the potentials directly from the His bundle and the right bundle branch.

\section{REFERENCES}

1. Rosen KM: The contribution of His bundle recording to the understanding of cardiac conduction in man. Circulation 43: 961, 1971

2. Castellanos A, Jr. Gastillo CA, Agha A et al: His bundle electrograms in patients with short P-R intervals, narrow QRS complexes, and paroxysmal tachycardias. Circulation 43:667, 1971

3. Mandel WJ, Danzig R, Hayakawa $\mathrm{H}$ : Lown-Ganong-Levine syndrome. A study using His bundle electrograms. Circulation 44: 696, 1971

4. Myerburg RJ, Nilsson K, Zoble RG: Relationship of surface electrogram recordings to activity in the underlying specialized conducting tissue. Circulation 45: 420, 1972

5. Scherlag BJ, Samet P, Helfant RH: His bundle electrogram. A critical appraisal of its uses and limitations. Circulation 46: 601,1972

6. Sano T, Nakai M, Suzuki F: Nature of His potential in His electrogram. Jap Heart J 13: 521,1972

7. Scherlag BJ, Lazzara R, Helfant RH: Differentiation of "A-V junctional rhythms ". Circulation 48: 304, 1973

8. Scherlag BJ, Lau SH, Helfant RH et al: Catheter technique for recording His bundle activity in man. Circulation 39: 13, 1969

9. Wolf GS, Freed MD, Ellison C: Bundle of His recordings in congenital heart disease. Brit Heart J 35: 805, 1973 
10. Narula OS, Scherlag BJ, Samet P: Pervenous pacing of the specialized conducting system in man. His bundle and A-V nodal stimulation. Circulation 41: 77, 1970

11. Rosen KM, Heller R, Ehsani A et al: Localization of site of traumatic heart block with His bundle recordings. Electrophysiologic observations regarding the nature of "split " $\mathrm{H}$ potentials. Am J Cardiol 30: 412, 1972

12. Rosen KM: His bundle electrogram. Circulation 46: 831, 1972

13. Gupta PK, Lichstein E, Chadda K: Electrophysiological features of complete AV block within the His bundle. Brit Heart J 35: 610, 1973

14. Narula OS, Samet P: Wenckebach and Mobitz type II A-V block due to block within the bundle and bundle branches. Circulation 41: 947, 1970

15. Narula OS, Scherlag BJ, Samet $\mathbf{P}$ et al: Atrioventricular block. Localization and classification by His bundle recording. Am J Med 50: 146, 1971

16. Rosen KM, Mehta A, Rahimtoola SH et al: Sites of congenital and surgical heart block as defined by His bundle electrocardiography. Circulation 44: 833, 1971

17. Schuilenburg RM, Durrer D: Conduction disturbances located within the His bundle. Circulation 45: 612, 1972

18. Gupta PK, Lichstein E, Chadda KD: Electrophysiological features of Mobitz type II AV block occurring within the His bundle. Brit Heart J 34: 1232, 1972

19. Varghese PJ, Elizari MV, Lau SH et al: His bundle elcctrograms of dog. Correlation with intracellular recordings. Circulation 48: 753, 1973

20. Langendorf R, Pick A: Atrioventricular block, type II (Mobitz)-its nature and clinical significance. Circulation 38: 819, 1968

21. Watanabe Y, Dreifus LS: Second degree atrioventricular block. In; Mechanisms and Therapy of Cardiac Arrhythmias (Dreifus LS, Likoff W, ed). Grune \& Stratton, New York, p 448, 1966

22. Rosen KM, Loeb HS, Gunnar RM: Mobitz II block without bundle-branch block. Circulation 44: 1111,1971

23. Tomaki Y, Matsuyama E, Nagamori S: Mobitz II type A-H block associated with complete block distal to the His bundle. Heart 5: 822, 1973 (in Japanese)

24. Spear JF, Moore EN: Electrophysiologic studies on Mobitz II second-degrec heart block. Circulation 44: 1087, 1971

25. Rosenbaum MB, Lepeschkin E: Bilateral bundle branch block. Am Heart J 50: 38 , 1955

26. Friedberg HD, Schamroth L: The Wenckebach phenomenon in left bundle branch block. Am J Cardiol 24: 591, 1969

27. Rosenbaum MB, Nau GJ, Levi RJ et al: Wenckebach periods in the bundle branches. Circulation 40:79, 1969

28. Scherf D, Shookhoff C: Reizleitungsstörungen im Bündel: II Mitteilung. Wien Arch Inn Med 11: 425, 1925

29. Cranefield P, Klein HO, Hoffman BF: Conduction of cardiac impulse. 1. Delay, block, and one-way block in depressed Purkinje fibers. Circulat Res 28: 199, 1971

30. Rusen KM, Rahimtoola SH, Chuquimia R et al: Electrophysiological significance of first degree atrioventricular block with intraventricular conduction disturbance. Circulation 43 : 491,1971

31. Ranganathan $\mathrm{N}$, Dhurandhar $\mathrm{R}$, Phillips JH et al: His bundle electrogram in bundle-branch block. Circulation 45: 282, 1972

32. Ali N, Wichramasekaran R, Fahdul $\mathrm{H}$ et al: Wenckebach periods in posterior inferior division of left bundle. Chest $63: 849,1973$ 